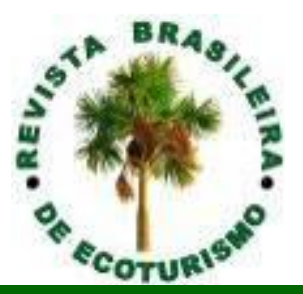

\title{
Turismo, museologia comunitária e economia criativa: um olhar sobre o projeto "Museu Comunitário: histórias de vida da Vila Embratel" (MA)
}

\section{Tourism, Community Museology and Creative Economy : A Look Into the Project "Community Museum: life stories of Vila Embratel" (MA, Brazil)}

\author{
Kláutenys Dellene Guedes Cutrim, Conceição de Maria Belfort de Carvalho
}

\begin{abstract}
RESUMO
O artigo faz uma reflexão sobre a temática museologia comunitária e para tanto busca um alinhamento de pensamento com outras áreas como o turismo, e a economia criativa. Para discorrer sobre essa composição de conhecimentos utilizase como objeto de reflexão a pesquisa intitulada Museu Comunitário: histórias de Vida da Vila Embratel. Com o referido projeto foi possível verificar de que maneira essas inicialmente consideradas distintas áreas podem somar para alcançar um objetivo em comum: o desenvolvimento de uma comunidade. O projeto visa fazer um levantamento de dados das potencialidades do bairro da Vila Embratel para a criação de um museu comunitário tendo como principal metodologia a pesquisa das histórias de vida dos moradores mais antigos do bairro. A basilar contribuição da pesquisa será construir junto com a comunidade um plano museológico que servirá como norte na construção do museu comunitário sob enfoque das teorias da economia criativa. É possível ao final da análise perceber que há probabilidade de um redimensionamento do turismo no sentido de possibilitar uma oferta diferenciada, com vistas a oferecer um produto interessante para a comunidade e para o turista na busca de desfazer preconceitos socialmente construídos.
\end{abstract}

PALAVRAS-CHAVE: Turismo; Museu Comunitário; Economia Criativa.

\section{ABSTRACT}

The article reflects on the theme community museology and to both search a thought of alignment with other areas such as tourism and the creative economy. To discuss the composition of knowledge is used as a research object reflection entitled Community Museum: Vila Embratel life stories. With this project we observed how these initially considered distinct areas can be added to achieve a common goal: the development of a community. The project aims to make a data collection of Vila Embratel neighborhood's potential for the creation of a community museum with the main methodology to research the life stories of the oldest residents of the neighborhood. The fundamental contribution of the research will build with the community a museum plan that will serve as north in the construction of community museum focus on the theories of the creative economy. It is possible the analysis of the final notice that there is a likelihood of a resizing of tourism in order to allow a differentiated offering, in order to offer an interesting product for the community and for tourists in search of undo socially constructed prejudices.

KEYWORDS: Tourism; Community Museum; Creative Economy. 


\section{Introdução}

O panorama que ora se apresenta é de profunda transformação nas relações sociais. O processo de mundialização do capital econômico e cultural, atrelado à disseminação de redes globais em amplos setores da realidade econômica proporciona a redefinição dos usos dos territórios, agencia as especificidades naturais e culturais das regiões e oportuniza o desenvolvimento social e econômico dessas localidades.

Na dinâmica atual a busca pelo simbólico das cidades tem levado a um interesse em ressignificar, a partir da preservação, os espaços, práticas e manifestações de reconhecido valor cultural para uma determinada comunidade. O desenvolvimento social e econômico é o objetivo principal que tende a ser alcançado através da valorização dos elementos indenitários e da paisagem natural.

Desse modo, muitas cidades e estados vêm procurando transformar o seu patrimônio - natural, histórico-arquitetônico, cultural, espiritual - em atrações turísticas, o que acontece na capital do estado do Maranhão, São Luís. Essa cidade apresenta potencialidades que podem sustentar fluxos diversos para vários tipos de turismo, dentre eles o do turismo cultural e suas mais variadas sub-tipologias tais como 0 turismo étnico, 0 gastronômico e o religioso.

Nesse sentido é que o Departamento de Turismo e Hotelaria da Universidade Federal do Maranhão, com financiamento do CNPq, propõe a realização de um projeto de pesquisa denominado Museu Comunitário: histórias de vidas na Vila Embratel, com o propósito de identificar na comunidade os moradores mais antigos para um resgate de suas memórias, identificar junto à comunidade objetos que tenham especial significado, ampliar as informações acerca das manifestações culturais existentes, entender a relação que possa existir dessas manifestações culturais e seus lugares de origem, visto que grande parte dos moradores da Vila Embratel é oriunda do interior do estado do Maranhão e até mesmo de comunidades quilombolas. O resultado desta pesquisa vislumbra a possibilidade de construção pela própria comunidade de um museu comunitário, cujo maior componente será a memória.

O diálogo com outras áreas de conhecimento se faz pertinente para desenvolver uma pesquisa dessa natureza visto que para se atingir um objeto tão complexo como é uma comunidade, e tentar somar no sentido de oferecer oportunidades de desenvolvimento, aqui compreendido no seu sentido mais amplo, faz-se necessário procurar entendimentos múltiplos oriundos não só das disciplinas oferecidas no curso de turismo (como patrimônio cultural, elementos de museologia, projetos turísticos e outros mais), como também necessita-se de um suporte teórico que possibilite olhares transversais para um objeto de pesquisa tão singular. Tal suporte foi encontrado na museologia comunitária e na economia criativa.

Para desenvolver a pesquisa em tela o universo analisado são os residentes do bairro da Vila Embratel. Para a definição do número de moradores a serem entrevistados, propõe-se uma amostra não probabilística por julgamento e exaustão. Serão incluídos na amostra os moradores mais 
antigos do bairro, preferencialmente os que estão no bairro desde a sua fundação.

$\mathrm{Na}$ realização e interpretação das entrevistas o método considerado mais apropriado é o de história de vida, método de pesquisa biográfico que busca elucidar a teia de relações existente entre a história individual e a história coletiva, em um contexto maior que é o social.

A partir das entrevistas, os informantes discorrerão sobre a existência de laços afetivos e simbólicos em relação ao bairro da Vila Embratel, identificando os lugares de memória, a dinâmica das relações - os usos sociais, as formas de apropriação do espaço pelos moradores, contando a sua história destacando possíveis artefatos de posse dos entrevistados. Além da narrativa dos entrevistados, serão consideradas algumas fotos, valiosos portadores da memória.

Nesse artigo não serão levados em conta os resultados da pesquisa que está em desenvolvimento, mas sim a sua relevância como exemplo do que pode ser feito por uma comunidade quando conhecimentos de áreas distintas possuem um mesmo foco, no painel específico dessa análise: museologia comunitária, turismo e economia criativa.

\section{Museus e turismo em São Luís: possibilidades para a museologia comunitária}

A partir da modernidade, segundo Berman (2007), iniciada no século $\mathrm{XVI}$, o mundo passou a experimentar um intenso processo de fragmentação, de desilusão, uma problematização dos valores sagrados, em que a razão passa a ser imperiosa. A noção de progresso, nesse período, passa a ter enorme relevância. Extremamente cultivado desde o lluminismo, o progresso leva a humanidade a problematizar os benefícios do desenvolvimento e o homem se põe a questionar até que ponto o desenvolvimento seria benéfico. Por isso, a memória surge como algo que deveria ser sustentado, caso se aspirasse por conservar certos aspectos da realidade.

O século $X X$, caracterizado por grandes turbulências, como as duas guerras mundiais, foi palco de inúmeras transformações que já se efervesciam desde o século XVIII: os valores científicos passaram, nesse momento, por profundas transformações, entre elas destacam-se as mudanças em noções como as de patrimônio cultural, o conceito de História, que se modificam com o advento da Nova História, bem como a mudança da compreensão do papel do sujeito, na sociedade, aspectos que reconfiguram a relação museu/história/memória. Nesse contexto, os museus refletem efetivamente essas mudanças de paradigmas, sentidas, por exemplo, no próprio conceito do que seria um museu.

O historiador Jacques Le Goff (2003) caracteriza os museus como instituições mantenedoras da organização da matéria memorável tendo como centro de suas preocupações as articulações entre o tempo, o espaço e o homem. Em uma perspectiva mais ampla, pode-se compreender as próprias instituições como instâncias da memória, isto é, como responsáveis por gestos fundadores que resultam da combinação da ação de um grupo. 
O museu é o reflexo de uma política previamente determinada, que estabelece desde a aquisição dos bens a serem expostos até as temáticas abordadas em exposições permanentes ou temporárias. A mensagem contida no acervo exposto pode ou não ser assimilada pelos visitantes. A receptividade por parte do público perpassa pela capacidade de conseguir que o visitante se sinta próximo, por uma ou outra razão, da memória materializada nos objetos museais.

No contexto local, o desenvolvimento da arte museal deu-se mais tarde. Apesar do título de Athenas Brasileira a capital do Estado não desperta ainda no século XIX para a preservação das identidades e memórias locais. Os novos olhares sob o patrimônio chegam um pouco mais tardiamente e, alinhando-se a esse contexto, surge a necessidade de preservar e representar a pujança maranhense do século XIX sendo então materializado esse desejo primeiramente em um amplo museu com coleções variadas que representam o patrimônio cultural local partindo da perspectiva da história dos vencedores.

Em São Luís, alguns estudos e reflexões vêm sendo realizadas com o intuito de apontar caminhos para a preservação das múltiplas identidades presentes no cenário formado a partir do patrimônio material e imaterial da cidade. No horizonte das políticas públicas de preservação do patrimônio cultural autores teorizam arduamente essa temática. Andrés (1998) centrase nas questões territoriais pertinentes ao traçado urbano do patrimônio de São Luís, voltando seu olhar para as políticas públicas de preservação, mas mantendo-se no limiar do olhar governamental. A não participação das comunidades nas decisões referentes ao processo de preservação do patrimônio material e imaterial é sinalizado por Guedes (2001), que analisa a trajetória das políticas locais de preservação e aponta a necessidade de permitir que o legado cultural, a memória e a história dos vários segmentos sociais que compõem esse cenário seja também conhecido por todos.

O termo patrimônio possui significações variadas; de forma mais simples, refere-se à posse de alguém sobre um bem ou um conjunto de bens. Esta propriedade pode ser de uma pessoa ou mesmo de uma comunidade, país e até mesmo do mundo.

Além da questão referente à posse, há outras variáveis que devem ser avaliadas quanto ao patrimônio. As considerações a respeito de patrimônio cultural, até o início deste século voltam-se totalmente para o patrimônio edificado, principalmente os que contivessem fatos históricos referentes a acontecimentos políticos considerados notáveis. Na busca mais recente de um conceito de patrimônio cultural o monumento isolado foi sendo preterido pelo conjunto de monumentos no sentido de abranger outras manifestações que representam os modos de pensar, agir e sentir da humanidade. $O$ artefato que possui valor de bem patrimonial guarda em si a representação de uma determinada época, comunidade ou mesmo de uma determinada moda.

Obviamente que além dos artefatos e de objetos tangíveis, a produção humana possui outros elementos que estão contidos em esferas não edificáveis, por exemplo, músicas, hábitos e costumes, vestuários, modos de falar, etc. Sendo assim, o patrimônio cultural inclui bens tangíveis e 
intangíveis oriundos de toda a vivência humana que pode ali materializar-se ou não, para representar as diversas culturas formadoras do complexo sociocultural.

A transformação da memória coletiva em patrimônio, em qualquer âmbito, inicia-se a partir da elaboração de uma escala de valores e termina com a determinação da sua sacralização. Este ato é forjado pela heterogeneidade de convicções, disputas e ideologias diversas. "Os patrimônios são constituídos a partir de processos de produção, apropriação, seleção e reelaboração simbólicas enquanto práticas sociais". (FONSECA, 1997) O turismo é visto com uma forma de preservação da cultura local aliando-se a isso o desenvolvimento econômico que pode advir da atividade.

Com base nas pesquisas divulgadas pelo Ministério do Turismo percebe-se que o segmento de turismo se torna ao longo dos anos crescente e de caráter otimista, pois os dados revelam que as 80 maiores empresas do setor de turismo no Brasil faturaram $R \$ 57,6$ bilhões e empregaram 115 mil pessoas nos 27 Estados brasileiros em 2012. O setor cresceu 13,1\% em 2012 em comparação ao ano anterior.

Segundo os dados da Infraero (Empresa Brasileira de Infraestrutura Aeroportuária), os aeroportos de São Luís (Marechal da Cunha Machado) e de Imperatriz (Renato Cortez) registraram movimento recorde no primeiro semestre de 2012. Foram 1.105.663 embarques e desembarques nos seis primeiros meses do ano, contra 981.753 em igual período de 2011, o que representa um crescimento de $12,64 \%$, com fluxos turísticos em percentuais maiores no mês de junho período de São João, festas juninas.

A visitação turística também se apresenta como um dos focos das preocupações das instituições museológicas para o desenvolvimento do turismo cultural visando retorno por parte do público visitante. Nesse tempo de grandes discussões acerca da pós-modernidade, da fragmentação das identidades e da necessidade de se resgatar memórias têm-se a necessidade de identificação de quem é a comunidade e sua atuação cultural.

O Estado do Maranhão considera-se apto a fazer parte dessa cadeia produtiva e busca se inserir nessa lógica, divulgando seu potencial turístico. A política para um desenvolvimento turístico inicia-se em 1993, com os recursos oriundos do Programa de Ação para o Desenvolvimento do Turismo no Nordeste - Maranhão (PRODETUR). Outros planos e programas somaram-se a esse e em 1999 foi iniciada a implementação do programa de desenvolvimento turístico denominado Plano Maior. Dentre as suas principais iniciativas está a criação de inúmeros museus, entretanto, todos com um olhar extremamente conservador.

No Brasil essa perspectiva, que tem como foco o objeto, tem seus alicerces abalados a partir do surgimento do MINOM - Movimento Internacional para uma Nova Museologia, que visa deslocar o foco das ações preservacionistas e redirecioná-lo para o ser humano, no sentido da coletividade e assim tornar o museu um espaço sensível às dinâmicas do mundo contemporâneo. O traçado histórico da construção desse processo teórico metodológico revolucionário pode ser verificado em documentos que colocavam o museu como parte fundamental de um processo de 
compromisso social e político na sociedade. Na América Latina podemos destacar documentos como a Declaração de Santiago do Chile em 1972, a Declaração de Oxatepec em 1984 e Caracas em 1982.

A museologia comunitária surge a partir da necessidade de ter a comunidade compreendendo e analisando a si mesmo na busca pelo resgate da memória coletiva através da valorização do potencial cultural e natural das comunidades. Em um museu comunitário a memória assume o papel de protagonista na contagem da história, na sua recriação e reinterpretação. No museu comunitário a ideia é que sejam firmados os valores descobertos por essa comunidade e que sejam contados da maneira como a comunidade assim decidir. O museu comunitário deve ser um instrumento para a construção de seres coletivos.

A Construção da coletividade perpassa por um autoconhecimento que pode se dar através de levantamento de histórias, de recolhimento de objetos, fotografias e desenhos, da realização de entrevistas que possibilitem a descoberta do olhar dessa comunidade sobre ela mesma. Ser o sujeito do processo é a condição natural do homem, como ressalta Paulo Freire. Em suas análises, o homem é sujeito porque é um ser de relações, capaz de refletir, de fazer crítica, de ser consciente de sua historicidade, de optar, de criar e transformar a realidade no itinerário das descobertas das suas potencialidades.

A cidade de São Luís possui uma diversidade cultural bastante significativa. Essa diversidade advém do processo histórico-social construído pelos grupos étnicos: branco, negro e indígena. A atividade turística que ora se desenvolve timidamente em São Luís, ainda acontece apenas nos roteiros tradicionais, em que a cultura é consumida em forma de espetáculos ou em fragmentos expostos nos locais com atratividade turística e nos museus da cidade. $O$ patrimônio cultural é apresentado, em sua grande maioria, a visitantes e residentes de maneira descontextualizada, sem considerar seus produtores. Quem são essas pessoas que fazem o Tambor de Crioula? Qual a dimensão do lúdico e do sagrado do Tambor de Mina? Não temos respostas para essas indagações, e manifestações como estas se fazem presente em grande parte das periferias de São Luís.

\section{Outros olhares sobre o bairro da Vila Embratel: Turismo, economia criativa e museus comunitários}

Dentre a numerosa área periférica da capital do Maranhão encontra-se o bairro da Vila Embratel, localizado a três quilômetros de distância do Centro de São Luís, à margem esquerda da BR- 135, em uma área denominada Itaqui-Bacanga, que forma um grande entorno da Universidade Federal do Maranhão. Na investigação da historicidade e origem da Vila Embratel existem muitas lacunas, porém sabe-se que a criação deste bairro teve como ponto de partida o remanejamento, feito pela própria UFMA, de ocupantes da sua atual área para bairros que atualmente compõem os arredores dessa instituição. Com o deslocamento destes moradores para um novo espaço foi feita a escolha do nome deste novo bairro, que por meio de plebiscito e participação da nova comunidade deram-lhe o nome de Vila 
Embratel, em função de haver ali a torre da Empresa Brasileira de Telecomunicações S/A (EMBRATEL).

Nesta comunidade é notória a presença de uma população mestiça com predominância do grupo étnico negro, que se traduz em diversos terreiros de religião de matriz africana denominada Tambor de Mina; grupos de Bumba-meu-boi, Tambor de Crioula, Capoeira, Tribos de índios (manifestação carnavalesca), artesanato, dentre outras atividades. Nesse contexto é que entendemos que a concepção de economia criativa é apropriada para organizar a produção cultural da Vila Embratel. Em razão das experiências da comunidade no que diz respeito à produção de suas manifestações culturais, com atores sociais que reúnem desde donas de casa, comerciantes, universitários a idosos que representam a autenticidade cultural do bairro. Em comunidades carentes como a Vila Embratel desenvolver programas e atividades que promovam a cultura da localidade é estimular os grupos sociais e suas identidades, que podem ser retratadas nos museus do tipo comunitários com atividades e pesquisas que abrangem os conceitos da economia criativa.

No âmbito da oferta cultural, os museus comunitários tendem a enriquecer a experiência turística, estreitando as relações entre turistas e residentes, e permitindo a democratização do acesso e o direito à memória de grupos sociais distintos. Constata-se ainda a tendência à retração da demanda turística pelo consumo de produtos padronizados e desterritorializados social e culturalmente, com a criação de roteiros, serviços e atrações que adquirem maior proximidade com o cotidiano e a tradição dos lugares visitados (SWARBROOKE; HORNER, 2002). Assim, em oposição à tendência à espetacularização dos lugares, celebrações e modos de vida, os turistas culturais tenderão a buscar roteiros, destinos e produtos capazes de oportunizar experiências tidas como únicas e provocadoras dos sentidos, com base em motivos, sensações e emoções, e na integração com a cultura das comunidades visitadas.

As preocupações com a função social do museu e das práticas museológicas, entretanto ainda não se fazem sentir em São Luís, mas as críticas ao modelo tradicional de museus que tem como foco o objeto se fazem pertinentes em uma cidade que se encontra dividida entre a riqueza e a exclusão.

Os indivíduos identificam-se com determinadas porções do território e estabelecem com eles relações de afetividade, tornando-os seus lugares de memória. É fundamental criar mecanismos que possam resgatar os conteúdos simbólicos a eles subjacentes, evitando-se a padronização e a cenarização da paisagem urbana e da cultura, possibilitando que a atividade turística se desenvolva concernente às expectativas e anseios da comunidade local. O processo de identificação dos sujeitos dá-se com o espaço no qual está inserida parte da memória, pois é através dela que vão ser registrados os meandros desta relação e as possíveis interações que irão surgir a partir desta identificação a ser gerada no indivíduo ou nos grupos sociais. O bairro, lugar onde se nasce, onde se é criado, onde se vive, significa tanto quanto a casa onde se mora. 
A dinâmica a que está sujeito um bairro representa a própria questão cultural, cujo significado nos remete ao grupo social, indivíduos comungando os mesmos significados, formando aquilo que se chama "comunidade de sentidos". Desta forma, a cultura está no universo das representações humanas. Para Castoriadis (1987, p.235), "na dimensão propriamente imaginária, a existência é significação. As significações podem ser demarcadas, mas não determinadas". Então, o bairro não é simplesmente um espaço físico, mas uma construção simbólica, uma forma de representação, portanto, um conjunto de valores, ideais, crenças, contradições, discursos, figuras, imagens, etc. $\mathrm{O}$ bairro está no âmbito da cultura.

No sentido de valorizar essas representações a economia criativa propõe a busca por alternativas que valorizem o intangível, o original, a diversidade cultural. Os museus comunitários adequam-se a esse paradigma quando se colocam como espaços criativos onde grupos sociais distintos podem externar as suas visões das suas histórias, das suas memórias, construindo coletivamente e de modo criativo alternativas para (re)criar a própria realidade.

No mundo e, sobretudo no continente americano, existe desde a década de 1970, um pensamento que busca mudanças nas práticas e procedimentos museais. No Brasil, o que podemos verificar é uma realidade que contradiz as visões reducionistas no que tange à presença de visitantes em museus. Verifica-se também um crescimento continuado de museus no Brasil. Mais especificamente percebe-se um aumento exponencial de museus de território e museus comunitários, sobretudo os museus de comunidades excluídas normalmente das políticas públicas, como as favelas. Com base nos dados disponíveis no Cadastro Nacional de Museus IBRAM/MINC (2010), verifica-se que a presença de museus ocorre de modo desigual pelo Brasil, destacando-se as regiões do Sudeste e Sul do país com maior quantitativo de unidades museológicas em média de $67 \%$ dos museus brasileiros. O Nordeste é a terceira região em quantitativo de museus, abrigando $21 \%$ do total de instituições mapeadas.

A construção, a descoberta do ser individual requer que vários mecanismos sejam utilizados. A criatividade como opositora do que já vem pronto é a grande ferramenta a ser utilizada na criação coletiva que é o cerne, o museu comunitário. A criatividade não coaduna com soluções prontas e acabadas. A pessoa, a comunidade criativa busca (re)inventar as formas de vivenciar a sua realidade. O museu Comunitário surge como um espaço aglutinador para organizar e impulsionar novas propostas e projetos comunitários a partir da criação coletiva, de dentro para fora. Sinalizando com a perspectiva de proporcionar uma equação coerente entre o manejo do patrimônio cultural através da valorização do ser e do saber local surge como alternativa o conceito de economia criativa que se origina, por sua vez, do termo indústrias criativas (REIS, 2012). Ainda segundo Reis, o conceito de economia criativa é um conceito em construção. Entendemos então que economia criativa não é necessariamente uma política cultural e nem tampouco uma tendência econômica. A economia criativa incentiva a utilização de termos e práticas funcionais que consigam desenvolver setores 
como os da arte, artesanato, moda, museus e outros mais que tenham a criatividade humana como seu principal objeto.

O autor John Howkins, consultor britânico, foi o primeiro a observar e descrever a dinâmica dessa economia no livro "The Creative Economy", de 2001, destacando a economia criativa diz respeito a atividades nas quais resultam em indivíduos exercitando a sua imaginação e explorando seu valor econômico. Para Santos-Duisenberg (2011), a economia criativa seria uma abordagem holística e multidisciplinar, lidando com a interface entre economia, cultura e tecnologia, centrada na predominância de produtos e serviços com conteúdo criativo, valor cultural e objetivos de mercado, resultante de uma mudança gradual de paradigma. Portanto, pode-se considerar que o valor imaterial, simbólico é primordial nesse conceito. $O$ valor, singular, único tanto para quem produz como para quem consome é fundamental nesse processo, nessa interface entre cultura, economia e tecnologia.

Existem, portanto, possibilidades de pensar a gestão do patrimônio sob a perspectiva da comunidade, enquanto alternativa aos modelos excludentes de revitalização do patrimônio. Uma dessas possibilidades pode ser 0 turismo cultural que deve ser entendido também como fenômeno sociocultural (BENI, 2002; GOULART; SANTOS; 1998) que, ao revelar para os moradores as especificidades do seu patrimônio cultural, propicia o fortalecimento da cultura e da memória local. Nesse patamar, considera-se ainda que o aproveitamento do patrimônio cultural pelo turismo deve incorporar as diretrizes da sustentabilidade em suas múltiplas dimensões social, economia, ambiental, cultural (SACHS, 1994; RODRÍGUEZ, 1997), a fim de possibilitar o envolvimento da comunidade e a preservação dos marcos urbano e práticas socioculturais mantenedoras de sua identidade. Portanto existem possibilidades da aplicação desses conceitos dentro do bairro da Vila Embratel. $O$ projeto em análise tende a confirmar essa assertiva.

\section{Museu Comunitario: histórias de vida da Vila Embratel}

O museu comunitário é um espaço coletivo que deve contar a história dessa coletividade tendo como atores principais do processo a comunidade. Portanto entende-se que o museu não deve necessariamente buscar uma história "vivida" no sentido de simulada, mas principalmente o seu compromisso primeiro deve ser de contador de histórias de vida.

No dizer das autoras Teresa Morales Lersch e Cuauhtémoc Camarena Ocampo (2004), o museu é sempre uma interpretação da vida, uma seleção específica e significativa da realidade. Quando não colocamos essa apreciação logo de saída, existe o perigo de ocultar a interpretação e o autor da interpretação. Podemos perguntar: o museu é a história vivida por quem? de acordo com quem?

No sentido de contribuir com a comunidade na qual a UFMA está inserida foi elaborada a pesquisa intitulada Museu Comunitário: Histórias de Vida da Vila Embratel entendendo-se que o método de pesquisa que melhor se adéqua para essa tarefa é o de viés qualitativo (MINAYO,1999; GOLDEMBERG,1998) com a utilização das seguintes técnicas qualitativas: a 
revisão bibliográfica, a pesquisa documental, a observação participante, as entrevistas e a utilização de fotografias e filmagens.

A primeira etapa que esta pesquisa contempla é a de cunho bibliográfico feita através de levantamentos de informações por meio de livros, revistas, site de internet, e outros. Nesta pesquisa, serão levantados aspectos históricos da região, bem como sua contextualização socioeconômica para a comunidade. Visando fomentar conhecimento sobre a formação do bairro da Vila Embratel desde sua constituição até os dias atuais.

A partir dos resultados desta pesquisa foi realizada a segunda etapa, que diz respeito ao levantamento qualitativo, por meio da realização das entrevistas. O método de pesquisa história de vida tem como a sua principal assertiva a existência do vínculo entre pesquisador e sujeito. Haguette (1992) sugere que o método de história de vida, dentro da metodologia de abordagem biográfica, proporciona a perspectiva da produção de sentido. Camargo (1984) complementa que o uso da história de vida possibilita apreender a cultura "do lado de dentro"; constituindo-se em instrumento valioso, uma vez que se coloca justamente no ponto de intersecção das relações entre o que é exterior ao indivíduo e aquilo que ele traz dentro de si. Cipriani (1988) corrobora quando considera o "livre fluir do discurso", condição indispensável para que vivências pessoais despontem profundamente entranhadas no social, o processo de "escavação do microcosmo" deixa entrever o "macrocosmo", o universal mostra-se invariavelmente presente no singular.

Depois de selecionados os sujeitos desta pesquisa, foi feita a aplicação de entrevistas. Para uma avaliação qualitativa, utilizou-se o método da técnica de entrevista. A sua utilização requer, no entanto, planejamento prévio e manutenção do componente ético, desde a escolha do participante, do entrevistador, do local, do modo ou mesmo do momento para sua realização (BICUDO, 2006). Para as entrevistas foram utilizadas perguntas semiestruturadas, gravadas por equipamento áudio visual/e ou de gravação e posteriormente transcritas para não comprometer a autenticidade das falas. Ressalta-se que nessa abordagem o entrevistado deve sentir-se completamente à vontade nos seus relatos.

O contato e a realização de entrevistas com os informantes ocorreram nas residências ou local de trabalho ou mesmo em outro local eleito. Ressalta-se ainda que foi realizado formalmente um pedido de autorização junto aos entrevistados, após a transcrição dos dados, para que a sua fala/fotografia seja utilizada para divulgação da pesquisa.

O norte na construção das entrevistas é o guia básico de educação patrimonial (HORTA; GRUMBERG; MONTEIRO, 1999) de acordo com o Quadro 1 a seguir: 
Quadro 1: guia básico de educação patrimonial.

Table 1 : Basic Guide to heritage education.

\begin{tabular}{|l|l|l|}
\hline PRESENTE & \multicolumn{1}{|c|}{ PASSADO } & $\begin{array}{l}\text { INFUENCIA DO PASSADO } \\
\text { NO PRESENTE }\end{array}$ \\
\hline Como é o lugar hoje? & $\begin{array}{l}\text { Como era esse lugar no } \\
\text { Passado? }\end{array}$ & $\begin{array}{l}\text { Que elementos do passado } \\
\text { podemos ver hoje? }\end{array}$ \\
\hline $\begin{array}{l}\text { Por que esse lugar é } \\
\text { assim hoje e como se } \\
\text { diferencia ou se } \\
\text { assemelha a outros } \\
\text { lugares? }\end{array}$ & $\begin{array}{l}\text { Por que este lugar era deste } \\
\text { modo no passado? } \\
\text { Como e por que ele se } \\
\text { diferenciava }\end{array}$ & $\begin{array}{l}\text { Que influências esses } \\
\text { elementos tiveram sobre este } \\
\text { lugar e de que modo essa } \\
\text { influência se diferencia ou se } \\
\text { assemelha ao que ocorreu em } \\
\text { outros lugares? }\end{array}$ \\
\hline $\begin{array}{l}\text { De que maneira esse } \\
\text { lugar se raciona a } \\
\text { outros lugares? }\end{array}$ & $\begin{array}{l}\text { De que maneira este lugar } \\
\text { estava relacionado a outros } \\
\text { lugares? }\end{array}$ & $\begin{array}{l}\text { De que modo as relações } \\
\text { existentes no passado } \\
\text { influenciaram esse lugar e de } \\
\text { que maneira ele se relaciona } \\
\text { hoje com outros lugares? }\end{array}$ \\
\hline $\begin{array}{l}\text { Como este lugar está } \\
\text { mudando por quê? }\end{array}$ & $\begin{array}{l}\text { Que mudanças ocorreram } \\
\text { neste lugar ao longo do } \\
\text { tempo por quê? }\end{array}$ & $\begin{array}{l}\text { Como as mudanças ocorridas } \\
\text { estão refletidas hoje nesse } \\
\text { lugar? }\end{array}$ \\
\hline $\begin{array}{l}\text { Como seria viver neste } \\
\text { lugar hoje? }\end{array}$ & $\begin{array}{l}\text { Como seria viver neste } \\
\text { lugar no passado? }\end{array}$ & $\begin{array}{l}\text { Como o passado influencia o } \\
\text { modo e a experiência de viver } \\
\text { neste lugar? }\end{array}$ \\
\hline
\end{tabular}

Fonte: Horta, Grumberg e Monteiro (1999, p.18).

Source: Horta, Grumberg and Monteiro (1999, p.18).

Com o intuito de encontrar as informações necessárias para gerar o produto principal dessa pesquisa, o plano museológico para a formação de um museu comunitário do bairro da Vila Embratel convida, dentre as pessoas mais antigas da comunidade, algumas que possam contribuir com as suas lembranças para a elucidação dos questionamentos em aberto em relação ao bairro.

Os informantes discorreram sobre a existência de laços afetivos e simbólicos em relação ao bairro da Vila Embratel, identificando os lugares de memória, a dinâmica das relações - os usos sociais, as formas de apropriação do espaço pelos moradores, contando a sua história apontando artefatos de posse dos mesmos que pudessem contribuir para a formação de um futuro museu comunitário. Além da narrativa dos entrevistados, as fotos, também são valiosos portadores da memória.

A terceira fase da pesquisa, foram as análises desses dados, de onde se extraiu informações acerca das memórias dos moradores do bairro da Vila Embratel, propiciando a identificação de suas principais características e de seus aspectos memoriais e principalmente fazendo emergir as suas histórias de vida. Todos os resultados foram estruturados em um relatório final de pesquisa que apresenta como produto final a geração de plano museológico para criação do museu comunitário da Vila Embratel. 


\section{O Patrimônio Cultural da Vila Embratel}

A memória humaniza o homem, pois dá a ele, a noção da sua identidade. Consegue articular na consciência, a ideia de que ontem, apesar de diferente de hoje, ele era o mesmo. A mesma coisa se dá em relação aos outros, pois, saber quem ele é implica também o reconhecimento dos outros. Significa que a cultura grava uma memória de fatos, eventos, nomes, cheiros, gostos etc. numa matéria física que é o cérebro. A memória é o limite entre o "eu"/ "nós" e o "outro".

O mesmo pode-se dizer da memória coletiva, ela é o que dá identidade a um povo. A cultura funda a identidade. Reconhecer-se como membro de uma comunidade, implica ter em si registros históricos daquela comunidade. O homem, enquanto ser localizado no espaço e no tempo, tem uma necessidade intrínseca de reviver o passado no presente, pois ele, enquanto ser simbólico, precisa reconhecer a si mesmo, aos outros e aos lugares que habita.

A memória é, segundo Le Goff (2003, p. 419), um "conjunto de funções psíquicas, graças as quais o homem pode atualizar impressões ou informações passadas, ou que ele representa como passadas".

Na memória reside a vitalidade da qual se fazem guardiões os grupos humanos vivos; a sua evolução permanente está sujeita à relação dialética entre o lembrar e o esquecer, inconsciente das suas deformações sucessivas vulneráveis a todas utilizações e manipulações, suscetível de longas latências e de súbitas revitalizações (NORA, 1984).

A memória de uma coletividade, além dos artefatos e de objetos tangíveis, possui outros elementos que estão contidos em esferas não edificáveis, por exemplo, músicas, hábitos e costumes, vestuários, modos de falar, etc. Sendo assim, o patrimônio cultural inclui bens tangíveis e intangíveis oriundos de toda a vivência humana que pode ali materializar-se ou não, para representar as diversas culturas formadoras do complexo sociocultural.

No intuito de descobrir como se deu o que hoje é patrimônio cultural, como ele foi se construindo, a comunidade inquirida comenta que eles trabalhavam em ritmo de união, pois para que o bairro fosse erguido esse contato gerou uma série de manifestações culturais pois no trabalho e no lazer a união era necessária. Eles tinham que construir suas residências com o pouco material ofertado, assim tinham que apoiar-se de forma mútua para alcançar um objetivo comum que era obter seus lares de forma digna.

\footnotetext{
"Era só mato, dificuldade com água, aí chegamos aqui e fomos receber os materiais que era só madeira, as palhas, a gente foi abrir palha pra fazer a casa, fizemos mesmo casa de taipa pra poder morar, pra nós se mudar pra cá a gente botou, não tinha, porta a gente colocou era pano, palha nas portas e janela. A gente ia por aqui, ia lá na UFMA, por aqui andando todo tempo por dentro do mato". (Sra. Maria de Fátima Araújo)
} 
A união da comunidade, e o sentimento de pertencimento do bairro podem ser atestados pelas inúmeras manifestações culturais existentes no bairro como apresentadas no Quadro 2 a seguir:

Quadro 2: tipos de danças existentes no bairro.

Table 2 : types of dances in the neighborhood.

\begin{tabular}{|c|c|c|}
\hline TIPO DE DANÇA & NOME DA DANCCA & DONO \\
\hline \multirow{6}{*}{ Bumba-meu-boi } & Novo Capricho ${ }^{1}$ & Marcílio \\
\hline & Brilho da Noite ${ }^{2}$ & Ribamar \\
\hline & Novo Oriente $^{3}$ & Glorinha \\
\hline & Riacho Doce 4 & Glorinha \\
\hline & Boi da Liberdade 5 & Claudionor \\
\hline & $\begin{array}{l}\text { Brilho da Noite de São João } \\
\text { Batista }^{6}\end{array}$ & Glória \\
\hline \multirow{6}{*}{ Quadrilhas } & Rancho Alegre (Meu Ranchinho) & Deomar \\
\hline & Flor de Maracujá & Mary \\
\hline & Flor do Sertão & Silvana \\
\hline & Alegria da Vila & Ubiraci \\
\hline & Flor da Jardineira & Marister \\
\hline & Flor da Vila & De menor \\
\hline \multirow{2}{*}{ Dança do Boiadeiro } & Menino Jesus ${ }^{7}$ & Glória \\
\hline & Country da Fé & Antoninha \\
\hline \multirow{3}{*}{ Dança Portuguesa } & Coimbra & Nonato (?) \\
\hline & $\begin{array}{l}\text { Cavaleiros de Portugal (mais } \\
\text { antiga) }\end{array}$ & Nabate \\
\hline & Vitória & Marinilde \\
\hline Dança Cultural & Pastor & Prof $^{\circ}$ Ferreira \\
\hline \multirow{3}{*}{ Tambor de Crioula } & Encantos do Maranhão & Mundé \\
\hline & Orgulho do Maranhão & Daniel Gaspar \\
\hline & Tambor de Crioula do Claudionor & Claudionor \\
\hline \multirow{2}{*}{ Cacuriá } & Cacuriá de Dona Ana & Ana \\
\hline & Cacuriá de Marinilde & Marinilde \\
\hline Dança da Fita & Dança da Fita & Zezé \\
\hline
\end{tabular}

Fonte: Elaborada pelas autoras.

Source: Prepared by the authors.

"A gente faz uma festa com a comunidade, mas os comerciantes locais apoiam culturalmente a festa aqui ajudam como podem. São quinze noites de festa, quinze noites que damos comida para o pessoal." (Sra. Mundica Estrela).

As inúmeras histórias que se entrelaçam nas memórias dos mais antigos possuem um denominador comum a todos, que é a dedicação e a vontade de ver o bairro prosperar. Tais indicadores podem ser facilmente identificados a partir da fala de todos os entrevistados que sempre pontuam aspectos ligados à luta pela sobrevivência e também o prazer que é viver naquela comunidade que eles ajudaram a construir, apesar das grandes dificuldades existentes até hoje.

É possível identificar também a grande ligação que existe entre os moradores mais antigos e as representações religiosas (católicas, evangélicas e de matrizes africanas). Essa ligação tão forte com as questões religiosas vai refletir sobremaneira nas manifestações culturais identificadas 
no bairro. É possível dizer também que o bairro, com o seu ranço de violência e descaso por parte do poder público, não se entrega ao conformismo, e as lutas iniciadas pelos primeiros moradores persistem através dos líderes comunitários atuais, em alguns casos constata-se que são os mesmos moradores.

Isto possibilita entender que a confluência gerada em torno do tempo, história, passado, memória e patrimônio não deve ser entendida de forma individual, mas sobre um olhar plural na busca de um espaço de sentido múltiplo, fruto de uma cultura diversificada.

Para Pellegrini,

modernamente se compreende por patrimônio cultural todo e qualquer artefato humano que, tendo um forte componente simbólico, seja de algum modo representado da coletividade, da região, da época específica, permitindo melhor compreender-se o processo histórico (1997, p.94).

Obviamente as significações dos lugares-memória são diferentes para os diversos setores sociais de um mesmo local; cada um possui características próprias que legitimam relações diferenciadas com 0 passado. O passado como memória não tem a mesma representação para todos, há de se atentar para os inúmeros significados que podem ser gerados a partir de um mesmo relato, seja ele oficial ou não.

A transformação da memória coletiva em patrimônio, em qualquer âmbito, inicia-se a partir da elaboração de uma escala de valores e termina com a determinação do tombamento. Este ato é forjado pela heterogeneidade de convicções, disputas e ideologias diversas. "Os patrimônios são constituídos a partir de processos de produção, apropriação, seleção e reelaboração simbólicas enquanto práticas sociais" (FONSECA, 1997, p.28).

A atribuição do valor, decorre em primeiro lugar, do julgamento do significado de algo para uma comunidade. Designar algo como patrimônio é uma atribuição à "coisa" em questão, para referir-se a uma importância simbólica nela existente.

Apesar das residências em sua maioria humildes, e de não encontrarmos monumentos de significância na perspectiva da estética, destacam-se alguns aspectos da história da Vila Embratel como lugares de memória relevantes para os moradores que acompanharam o surgimento e crescimento do bairro: Praça Sete Palmeiras, Torre da Embratel, Terreiro de Mundica Estrela, Praça do Bacurizeiro.

"A praça, não tinha praça, não tinha a praça do Bacurizeiro, não tinha a praça Sete Palmeiras, hoje já tem tudo. A Igreja Católica, eu lembro que a Igreja Católica eles fizeram duas vezes e todas as duas vezes caiu, porque eles estão fazendo com a frente pro lado daqui e quando acaba era pra ser com a frente pro lado de lá, pro lado da praça Sete Palmeiras". (Entrevistado no15). 
Destacam-se também os principais marcos históricos, considerados pelos moradores, como de maior relevância, quais sejam: a mudança para o bairro transferidos do Sá Viana para próximo a Torre da Embratel; a doação do terreno pela Universidade, sendo que foram emitidos 389 escrituras de posse; a construção do chafariz a partir do núcleo de esporte da universidade, bem como a doação de materiais feita pela universidade para os novos moradores; a construção do chafariz; a construção da União de moradores com a colaboração do sr. Raimundo Mendes Barata; a inclusão do CEMA através da TVE, onde foram ministradas vídeo aulas a pedido da comunidade; a fundação da escola Henrique de La Roque que foi a primeira escola da Vila Embratel.

A materialidade da história do bairro pode ser atestada através de poucos, mas significativos artefatos guardados por essas pessoas que dividiram as suas histórias conosco.

$\mathrm{Na}$ busca de materialidades e imaterialidades que pudessem contribuir resultado dessa pesquisa percebemos que todas essas histórias e pessoas são passiveis de serem representadas em um espaço museal. Os artefatos, as histórias, as lutas, as vitórias, as derrotas os locais que serviram de marco nesse processo de formação desse bairro, na vida dessas pessoas tudo isso é muito digno de ser repassado para as gerações que talvez não (re)conheçam o valor dos seus ascendentes. Bourriaud (2006, s/p) diz que

no século passado, o futuro era o modelo de leitura do presente, hoje, talvez o passado seja o modelo de leitura. Isto ocorre por conta da padronização do planeta que apaga a memória, e a melhor forma de lutar contra isso é não voltar ao passado, mas ler o passado no presente, buscar novos itinerários no passado e isso é muito importante.

\section{Considerações finais}

A partir dessa análise compreende-se que esse estudo busca uma alternativa aos modelos excludentes de revitalização do patrimônio e gestão do turismo, na medida em que se pretende enveredar na elucidação de um espaço que está alijado das políticas de preservação locais, o bairro da Vila Embratel. O mapeamento das representações contidas nesse espaço simbólico possibilitará a análise das potencialidades para a criação de um museu comunitário no referido bairro e assim contribuir para o fortalecimento dos grupos socioculturais existentes naquela região, conhecida como Eixo Itaqui-Bacanga. O norte teórico a ser utilizado é a concepção semiótica da cultura (GEERTZ, 1997) onde os grupos sociais são compreendidos como seres simbólicos e o seu patrimônio só pode ser compreendido a partir da lógica do sistema cultural no qual eles estão inseridos.

As políticas públicas devem sempre buscar inserir as comunidades locais no processo da efetivação do turismo possibilitando assim que a atividade contribua para o revigoramento das economias. Portanto, um projeto que visa ter o turismo como vetor de desenvolvimento sustentável 
pode contribuir para a articulação e mobilização comunitária em prol da elevação de suas condições de vida, promovendo intercâmbios, gerando aprendizado e desenvolvendo o espírito empreendedor, baseando-se nas economias criativas e enaltecendo o sentido de lugar (YÁZIGI, 2001).

A inserção social atrelada à melhoria da qualidade de vida dos segmentos populares e a visão em longo prazo, compartilhada em níveis de corresponsabilidade e integração entre os agentes e a manutenção da dinâmica das culturas e valores locais, são fundamentais para um sustentável relacionamento entre turismo e patrimônio cultural (SACHS, 1994). Observa-se que o aproveitamento do patrimônio pela atividade turística deve considerar os elementos definidores dos espaços urbanos e naturais sob o olhar da comunidade, incrementando a oferta local com roteiros, serviços e produtos que enalteçam a vivência dos turistas no destino, além de enfatizar o protagonismo da comunidade em áreas de interesse turístico (MURTA; ALBANO, 2002).

No contexto atual, as identidades tornam-se móveis, fluidas, e se constroem no jogo dialético e dinâmico das relações sociais (HALL, 2001), no qual o turismo está inserido. As reflexões acerca dessa temática nos conduzem para o entendimento sobre as potencialidades que existem no bairro da Vila Embratel e das possibilidades que existem para a comunidade local tanto no que concerne ao desenvolvimento sócio econômico quanto ao fortalecimento de identidades e pertencimentos que talvez hoje se encontram adormecidos. A criação de um museu comunitário é uma alternativa de desenvolvimento para uma comunidade, a partir de uma perspectiva criativa.

A economia criativa tem como sistemática básica a produção, difusão e distribuição de produtos e serviços que usam a criatividade como foco principal. Os princípios da economia criativa estão pareados aos de desenvolvimento sustentável, pois ambos visam o desenvolvimento através da inclusão de setores que até então estariam fora da cadeia produtiva.

Mas como trabalhar o conceito de um museu comunitário a partir do olhar capitalista da economia criativa? Se entendermos que o museu pode ser um agente de desenvolvimento para a sua comunidade que trabalhe de forma inclusiva é possível falar sim dessa parceria que se baseia na cultura, na consciência do particular, do local, em uma espécie de contrapartida à globalização (PRIMO, 1999, p.28)

$\mathrm{Na}$ busca do desenvolvimento de uma comunidade é preciso considerar opções que se tornem viáveis para todos os envolvidos no processo. Na junção das variáveis de museus comunitários e economia criativa vislumbra-se a possibilidade do desenvolvimento de um museu comunitário como um local aglutinador de saberes e representações, e o bairro da Vila Embratel apresenta-se como um espaço promissor para a realização dessa categoria de atividade museal inclusiva e criativa e para 0 desenvolvimento de uma categoria de turismo cultural que tem como foco mostrar um conteúdo implícito nas entrelinhas do patrimônio construído por comunidades que ainda não se permitiram reconhecer o seu próprio valor. 


\section{Referências bibliográficas}

ANDRÉS, L.F.C.C. et al. Centro Histórico de São Luís - Maranhão: Patrimônio Mundial. São Paulo: Audichoromo, 1998.

BENI, M.C. Análise Estrutural doTurismo. São Paulo: SENAC, 2002

BERMAN, M. Tudo que é sólido desmancha no ar: a aventura da modernidade. Tradução de Carlos Felipe Moisés e Ana Maria L. Ioriatti. 2. ed. São Paulo: Companhia das Letras, 2007.

BICUDO, M.A.V.. Pesquisa qualitativa e pesquisa qualitativa segundo a abordagem fenomenológica. In: BORBA, M.C.; ARAÚJO, J.L. (Org.) Pesquisa qualitativa em educação matemática. Belo Horizonte: Autêntica, 2006.

CAMARGO, A. Os Usos da História Oral e da História de Vida: trabalhando com elites políticas. Dados - Revista de Ciências Sociais. Rio de Janeiro, 1984.

CASTORIADIS, C. O imaginário e a criação no domínio do social-histórico. In: CASTORIADIS, C. As Encruzilhadas de labirinto / 2 - Rio de Janeiro. Paz e Terra.1987.

CIPRIANI, R. (1988) Biografia e Cultura - da religião à política. In: VON SIMSON, O (org.). Experimentos com Histórias de Vida: Itália-Brasil. São Paulo: Vértice

FONSECA, M.C.L. Patrimônio em processo: trajetória da política federal da preservação no Brasil. Rio de Janeiro, UFRJ/MINC/IPHAN, 1997.

FUNARI, P.P.; PINSKY, J. (Orgs). Turismo e Patrimônio Cultural. São Paulo: Contexto, 2007.

GEERTZ, C. O saber local: novos ensaios em antropologia interpretativa. Petrópolis, RJ: Vozes, 1997.

GOLDENBERG, M. A arte de pesquisar. Como fazer pesquisa qualitativa em Ciências Sociais. Rio de Janeiro: Record, 2005.

GOULART, M.; SANTOS, R.I.C. Uma abordagem histórico-cultural do turismo. Turismo -Visão e Ação, v. 1, n. 1, p. 19-28, jan./jun. 1998.

GUEDES, K.D.B. Políticas de Preservação do Centro Histórico de São Luís. Dissertação de Mestrado, Recife: UFPE, 2001.

HALL, St. A identidade cultural na pós-modernidade. Rio de Janeiro: DP\&A editora, 2001.

HAGUETTE, T.M.F. Metodologias qualitativas na Sociologia. 3.ed.rev. e atual. Petrópolis: Vozes, 1992, 224p.

HORTA, M.L.; GRUNBERG, E.; MONTEIRO, A.Q. Guia Básico de Educação Patrimonial. Brasília: IPHAN e Museu Imperial,1999.

Instituto Brasileiro de Museus em Números/lnstituto Brasileiro de Museus Brasília: Instituto Brasileiro de Museus, 2011. 240 p. Disponível em: http://www.museus.gov.br/. Acesso em: 28.10.2013

LE GOFF, J. História e Memória. Campinas: Unicamp,2003.

MINAYO, M.S. O desafio do conhecimento: pesquisa qualitativa em saúde. São Paulo: Hucitec; Rio de Janeiro: Abrasco, 1999. 
MURTA, S.M.; ALBANO, C. (Orgs.). Interpretar o patrimônio: um exercício do olhar. Belo Horizonte: Ed UFMG, 2002.

NORA, P. Entre memória e história: a problemática dos lugares. Projeto História, São Paulo, 1993.

OCAMPO, C.C.; LERSCH, T.M. Los museos comunitários como una estratégia de desarrollo y conservación.. In: POSSAMAI, Z.R. Cidade e memória na globalização Porto Alegre: Unidade Editorial da Secretaria Municipal de cultura, 2002.

PRIMO, J.S. Declaração de Caracas. Cadernos de Sociomuseologia: museologia e patrimônio: Documentos Fundamentais. Lisboa. Universidade de Lusófona n 15, 1999.

REIS, A.C.F. Cidades Criativas: da teoria à prática, São Paulo: SESI-SP 2012 RODRIGUÉZ, J.M.M. Desenvolvimento Sustentável: níveis conceituais e modelos. In: CAVALCANTI, A.P.B. (Org.). Desenvolvimento Sustentável e planejamento: bases teóricas e conceituais. Fortaleza: UFC - Imprensa Universitária, 1997.

SACHS, I. Estratégias de transição para o século XXI. Desenvolvimento e meio ambiente. São Paulo: Nobel, 1994.

SANTOS-DUISENBERG, E. Temos muito mais a oferecer do que café, suco e minério. Disponível em: http://economia.ig.com.br/empresas/unctad+temos+muito+mais +a+oferecer. Acesso em 16/10/2011.

SWARBROOKE, J.; HORNER, S. O comportamento do consumidor no turismo. São Paulo, Aleph, 2002.

YÁZIGI, E. A alma do lugar: Turismo, planejamento e cotidiano. São Paulo: Contexto, 2001.

Kláutenys Dellene Guedes Cutrim: Universidade Federal do Maranhão, São Luís, MA, Brasil.

E-mail:kdguedes@yahoo.com.br.

Link para o currículo Lattes: http://lattes.cnpq.br/4310600393313804

Conceição de Maria Belfort de Carvalho: Universidade Federal do Maranhão, São Luís, MA, Brasil.

E-mail: cbelfort@globo.com.

Link para o currículo Lattes: http://lattes.cnpq.br/7821541616565704

Data de submissão: 28 de abril de 2015

Data de recebimento de correções: 17 de agosto de 2015

Data do aceite: 17 de agosto de 2015

Avaliado anonimamente 